\title{
Sentidos do diagnóstico por câncer de mama feminino para casais que 0 vivenciaram ${ }^{*}$
}

Cintia Bragheto Ferreira ${ }^{1}$

Ana Maria de Almeida ${ }^{2}$

Emerson Fernando Rasera ${ }^{3}$

\section{Introdução}

O câncer de mama é uma doença que todos os anos acomete inúmeras mulheres. O Instituto Nacional do Câncer (INCA) aponta, para 2008, a ocorrência de 49.400 novos casos (Brasil, 2008), o que constitui um problema de saúde pública.

A confirmação do diagnóstico por câncer de mama gera, na mulher doente, a reflexão e o questionamento sobre as relações interpessoais estabelecidas por ela (Vieira, Queiroz, 2006), bem como medo, incerteza, sintomas de ansiedade, depressão (Ryan et al., 2005) e sentimentos de horror, impacto e pânico (Cardozo, 2002). Além disso, a maior preocupação dessas mulheres se fixa em se manterem vivas fisicamente e, ao adquirirem consciência sobre o que têm, se apegam à religiosidade com o intuito de ter forças para realizar o tratamento (Nogueira, 2004). A relação com o mundo divino também foi encontrada num estudo de Teixeira e Lefèvre (2007), ao investigarem a religiosidade no trabalho de enfermeiras da área oncológica, no qual elas percebem a importância dessa crença nos pacientes que cuidam, ao relatarem que: o momento crítico representado pelo câncer aproxima os pacientes de Deus, os ajuda no processo de cura e de aceitação da doença.

O anúncio da confirmação do câncer a uma mulher, geralmente, ocorre quando ela está sozinha, visto que, quando acompanhada de seu companheiro, este não é valorizado para entrar com ela na consulta, porque ele pode causar um gasto maior de tempo, ou por suas perguntas ou pela necessidade de ambos serem consolados, em conseqüência do impacto do diagnóstico de câncer.

O momento do diagnóstico é relembrado, pelas mulheres acometidas, como uma experiência dramática (Saegrov, Halding, 2004), e considerado o mais estressante de todos (Epping-jordan et al., 1999), estando associado à insegurança e incerteza tanto em relação ao tratamento e sua eficácia quanto à convivência com a falta da mama e suas conseqüências para o relacionamento conjugal (Rossi, Santos, 2003).

Os companheiros das mulheres com câncer tendem, muitas vezes, a vivenciar esse momento com surpresa, devido à realização dos exames periódicos delas, 0 que parece ser uma garantia de prevenção de qualquer doença, inclusive o câncer.

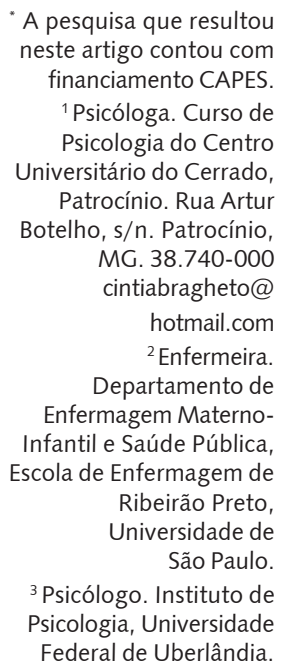

A pesquisa que resultou neste artigo contou com financiamento CAPES. 1 Psicóloga. Curso de Psicologia do Centro Universitário do Cerrado, Patrocínio. Rua Artur Botelho, s/n. Patrocínio, MG. 38.740-000 cintiabragheto@ hotmail.com ${ }^{2}$ Enfermeira. Departamento de Enfermagem MaternoInfantil e Saúde Pública, Escola de Enfermagem de Ribeirão Preto, Universidade de São Paulo.

${ }^{3}$ Psicólogo. Instituto de Psicologia, Universidade Federal de Uberlândia. 
Além disso, os mesmos podem sentir desesperança, impotência, intranqüilidade e medo de perderem suas esposas (Gradim, 2005; Picard et al., 2005), mas tendem a pensar positivamente (Cerqueira, 2004).

Freqüentemente, percebe-se que a preocupação dos profissionais da área da saúde que lidam com mulheres com câncer de mama direciona-se preferencialmente a elas. Não se atenta, muitas vezes, para as relações dessas mulheres com os outros membros de suas famílias, ao assisti-las a partir do adoecimento por câncer de mama.

A compreensão da experiência das mulheres e seus maridos, ao receberem a confirmação da doença, por exemplo, é um tipo de relação para a qual, no Brasil, ainda há poucos estudos capazes de auxiliar nesse entendimento. Estudos como o de Cerqueira (2004) apresentam as reações emocionais de casais, diante do diagnóstico do câncer de mama da parceira, e as formas de enfrentamento da doença, porém não é um estudo que revela os sentidos da doença para os casais entrevistados. O trabalho com a busca de sentidos pode ampliar o universo de entendimento dos fenômenos de pesquisa, na medida em que, além das emoções, a cultura e a história também são relevantes para a compreensão dos objetos de pesquisa. Além disso, o momento do diagnóstico por câncer de mama é estudado apenas com a mulher que o recebe, assim como é demonstrado nos estudos de Vieira e Queiroz, 2006, Ryan et al., 2005, Nogueira, 2004, Saegrov e Halding, 2004, e Epping-jordan et al., 1999.

O estudo do casal diante da confirmação do câncer de mama da parceira apresenta-se relevante para se avançar na compreensão dos sentidos que esses casais constroem para lidar com a enfermidade e, assim, construir práticas para assisti-los nos serviços de saúde.

\section{Câncer: sentidos associados}

O surgimento do cristianismo influenciou, de forma relevante, o significado do câncer, ao moralizálo, associando-o a um doente vitimizado por uma enfermidade que podia ser um castigo até justo e adequado (Sontag, 2007).

No século XIX, a idéia da doença como punição foi substituída pela noção de que a enfermidade expressa o caráter do doente. Essa versão coloca o doente não mais na posição de vítima, mas de culpado pela sua doença. $O$ doente passa a ser visto como um indivíduo que não conseguiu dar vazão às suas emoções, isto é, uma pessoa que fracassou em sua expressividade (Sontag, 2007).

Dando continuidade à noção de que o doente é culpado pela sua enfermidade, há ainda a crença de que o câncer seria uma doença adquirida por meio da sujeira, assim como a sífilis, uma "sujeira" não só do corpo, mas da alma também. Dessa forma, o doente teria de suportar seu sofrimento de forma isolada até a morte, por sofrer de uma enfermidade inglória (Sant'anna, 1997).

Em nossa sociedade, é muito freqüente, também, a associação do câncer a experiências muito desagradáveis como, por exemplo, a violência e a corrupção, que são acontecimentos que perturbam a ordem social e, por isso, recebem a denominação de câncer (Gomes, Skaba, Vieira, 2002) - e parecem, assim como a doença, não serem investidos de expectativas positivas de resolução. Apesar dos avanços para a detecção precoce e tratamento do câncer, persiste ainda o simbolismo de uma doença invasora, misteriosa e geradora de sofrimento e perdas (Aquino, Zago, 2007; Sontag, 2007). Concordando, assim, com os resultados de uma recente pesquisa realizada, que, ao investigar a concepção dos brasileiros sobre o câncer, mostra que, em termos emocionais, a doença é predominantemente associada à morte, à tristeza, à dor, ao medo e a uma maldição. Além disso, a maioria da população brasileira não considera que a falta de atividade física, a não-utilização de preservativos nas relações sexuais e a alimentação inadequada possam causar a doença (Brasil, 2007).

Os dados encontrados nessa pesquisa são relevantes para a reflexão sobre quanto o câncer ainda é uma enfermidade cujas metáforas são dependentes da história da própria doença ao longo dos tempos, independentemente dos avanços da medicina, os quais parecem não ser capazes de possibilitar aos indivíduos a construção de sentidos positivos associados a essa enfermidade, e nem de conceberem que a adoção de hábitos saudáveis de vida pode ser um fator de prevenção da doença.

Sendo assim, será que a negatividade que permeia o câncer também participou das construções discursivas dos casais entrevistados para o câncer de mama da parceira e os influenciou, ao se relacionarem com a doença? 


\section{Objetivos}

Descrever e analisar os sentidos que casais constroem sobre o câncer de mama da parceira e sobre as formas de se relacionar com o adoecimento por essa patologia.

\section{Referencial teórico e metodológico}

A busca pela compreensão dos sentidos construídos por casais para o câncer de mama da parceira se aproxima da investigação qualitativa, em virtude de sua função estar na descrição de um processo, e não de um produto que, de acordo com Mayan (2001), explora as experiências das pessoas em sua vida cotidiana, tal como esta se apresenta, sem sofrer interrupções.

O referencial teórico do construcionismo social permeou esta investigação. Gergen (1997) apresenta que o construcionismo social possui, como foco de compreensão, as relações sociais, as quais são dependentes da história e do contexto de vida das pessoas (Rey, 2002), e não o psíquico desses indivíduos, assim, o essencial é o resultado das trocas sociais desses últimos. Outros autores, como Spink e Medrado (2000), ainda afirmam que o construcionismo social é um referencial que se interessa pela identificação dos processos por meio dos quais as pessoas "descrevem, explicam e/ou compreendem o mundo em que vivem, incluindo elas próprias".

Especificamente neste estudo, a compreensão dos sentidos construídos por casais para o câncer de mama da parceira pautou-se nas proposições do construcionismo social na perspectiva de que vivemos:

num mundo social que tem uma história. Os repertórios interpretativos que nos servem de referência foram histórica e culturalmente constituídos. Trabalhar no nível da produção de sentidos implica retomar também a linha da história, de modo a entender a construção social dos conceitos que utilizamos no métier cotidiano de dar sentido ao mundo. (Spink, Medrado, 2000, p.49)

Dessa maneira, o construcionismo social é um referencial teórico que se articula com a abordagem qualitativa de pesquisa, ao utilizar conceitos como a história, o contexto e o processo no entendimento da constituição dos fenômenos, os quais, no nosso estudo, são os sentidos que casais constroem para o câncer de mama da parceira e como eles se relacionam com esse adoecimento.

Nesta investigação, foram entrevistados sete casais, número definido pelo critério de saturação dos dados, o qual define que as entrevistas devem ser realizadas até que as falas dos participantes comecem a se repetir (Ferreira, 2003). As mulheres participantes freqüentam um serviço especializado para reabilitação de mastectomizadas, localizado num município do interior paulista.

Os casais foram convidados, inicialmente, por meio das esposas que freqüentavam o referido serviço, durante a realização da dinâmica de grupo, que é uma das atividades assistenciais oferecidas. As mulheres que aceitaram participar foram solicitadas a estender o convite a seus parceiros para, então, ambos participarem do estudo. Aos casais que aceitaram participar, foi informado que seriam realizadas entrevistas agendadas, previamente, de acordo com a disponibilidade deles, em local adequado, e que essas entrevistas teriam duração média de 60 minutos, seriam gravadas em um microgravador e transcritas posteriormente. Registra-se que este estudo foi submetido a um Comitê de Ética em Pesquisa ao qual pertence o referido serviço e, ainda, que foi assinado, por cada entrevistado, o termo de consentimento pós-informado.

Participaram mulheres que haviam finalizado o tratamento proposto para o câncer de mama, há pelo menos um ano do período em que foram convidadas para a pesquisa, e estivessem sem a manifestação de nenhuma metástase na época do convite; e participaram também os maridos dessas mesmas mulheres. Além disso, considerou-se casal quando os participantes assim se intitulavam sem, portanto, a necessidade do registro do casamento em cartório.

As entrevistas realizadas com esses casais foram do tipo semi-estruturada e, para ambos, foram feitas as mesmas perguntas, as quais se referiram ao câncer e às formas de lidar com o diagnóstico da doença. 
Ao término das entrevistas, iniciou-se a análise dos dados, a qual está inserida na proposta de prática de pesquisa proposta por Spink (2000), que utiliza a definição de sentido como uma construção dialógica, situada cultural e historicamente. Contudo, não foi utilizada a técnica que a mesma autora propõe para a análise de dados, como os mapas de associação de idéias e gráficos, em virtude de a preocupação dos pesquisadores estar centrada muito mais no aprofundamento de compreensão dos dados coletados do que em sua apresentação repetitiva.

Todas as entrevistas foram transcritas (quando cada integrante da díade recebeu nomes fictícios), com base na adaptação do modelo proposto por Schiffrin (1994), e lidas de forma flutuante, para que os principais temas das entrevistas pudessem emergir (Spink, Lima, 2000). Essas leituras ocorreram de forma exaustiva, o que proporcionou que os sentidos do diagnóstico por câncer de mama feminino para os casais aflorassem e, assim, pudessem ser compreendidos.

\section{Resultados e discussão}

No período de realização das entrevistas, os participantes deste estudo contavam com uma média de tempo de união de 34 anos. A maioria dos entrevistados, tanto homens (seis) quanto mulheres (seis), possuía até oito anos de estudo. Grande parte se intitulou como católica (seis mulheres e cinco homens) e uma minoria como espírita (uma mulher e dois homens). Juntos tiveram, em média, dois filhos. A média de idade dos casais, quando da realização das entrevistas, era de 62 anos, e a média de tempo de cirurgia das mulheres, no momento de realização das entrevistas, era de cinco anos (Quadro 1). Serão apresentadas as falas dos entrevistados relacionadas ao momento de confirmação do câncer, o qual afetou maridos e esposas que associaram o diagnóstico da doença aos sentidos de provação e de morte. Esses sentidos despertaram, nos participantes, sentimentos, como a revolta e a ansiedade, que puderam ser amenizados na relação dos casais com o mundo divino. A partir das questões norteadoras: O que você fez e/ou pensou para ultrapassar o momento de confirmação da doença? Como você lidou com esses momentos?

Quadro 1. Caracterização dos casais estudados.

\begin{tabular}{|c|c|c|c|c|c|c|c|}
\hline Variáveis & \multicolumn{7}{|c|}{ Casais entrevistados } \\
\hline $\begin{array}{l}\text { Identificação } \\
\text { dos casais } \\
\text { (nomes fictícios) }\end{array}$ & $\begin{array}{c}\text { Joana e } \\
\text { Raimundo }\end{array}$ & Lúcia e Paulo & $\begin{array}{l}\text { Lourdes e } \\
\text { Mauro }\end{array}$ & $\begin{array}{l}\text { Nilde e } \\
\text { Roberto }\end{array}$ & $\begin{array}{l}\text { Marta e } \\
\text { Valmir }\end{array}$ & Rute e Júlio & $\begin{array}{l}\text { Guiomar e } \\
\text { Pedro }\end{array}$ \\
\hline Tempo união (anos) & 16 & 38 & 43 & 37 & 37 & 27 & 43 \\
\hline $\begin{array}{l}\text { Religião } \\
\text { Mulher } \\
\text { Homem }\end{array}$ & $\begin{array}{l}\text { católica } \\
\text { espírita }\end{array}$ & $\begin{array}{l}\text { católica } \\
\text { católica }\end{array}$ & $\begin{array}{l}\text { espírita } \\
\text { espírita }\end{array}$ & $\begin{array}{l}\text { católica } \\
\text { católica }\end{array}$ & $\begin{array}{l}\text { católica } \\
\text { católica }\end{array}$ & $\begin{array}{l}\text { católica } \\
\text { católica }\end{array}$ & $\begin{array}{l}\text { católica } \\
\text { católica }\end{array}$ \\
\hline $\begin{array}{l}\text { Tempo de cirurgia } \\
\text { (anos) }\end{array}$ & 3 & 4 & 11 & 9 & 3 & 3 & 4 \\
\hline
\end{tabular}


Percebe-se, nas falas de Guiomar (casal 7) e Roberto (casal 4), apresentadas a seguir, os sentidos do câncer como uma provação que os levou ao diálogo com Deus:

Olha, no início foi barra pesada [...] porque eu achava até que era um castigo [...] depois que eu fui vê não Deus é, num castiga ninguém não, cada qual tem que passá por alguma coisa que, então, num fui tanto que, no início eu nem falava no assunto com as pessoas, agora não, agora eu converso, falo pra qualqué pessoa. (Guiomar, casal 7)

Visualiza-se que Guiomar (casal 7) só conseguiu falar sobre seu câncer ao ressignificar o sentido de provação emprestado a ele como um castigo, assim como apresenta Sontag (2007) para algo que pode ser comparado a qualquer outro problema, e, dessa forma, ela rompeu o silêncio e o isolamento como lugares historicamente reservados às pessoas com câncer (Sant'anna, 1997): “Eu falava pra ela que esse problema de doença isso aí qualqué um de nós tamo sujeito e que devíamos aceitá se era um desígnio de Deus! Nós tínhamos que passá por essa provação" (Roberto, casal 4).

A confirmação do câncer de mama esteve associada ainda à possibilidade da morte, provocando, nos entrevistados, uma paralisia para a esperança de um resultado positivo, ou seja, de que poderia existir vida a partir do diagnóstico da doença. No caso de Nilde (casal 4), houve uma preparação concreta para esperar a chegada da morte, como se acompanha nos recortes a seguir: "Eu vô morrê!... Dexei tudo a casa em ordem, roupa, porque o dr. disse que eu ia entrá em cirurgia com dez por cento de sobrevida, eu pensei assim, eu morro, vão tê que fazê velório pra mim, essa casa toda bagunçada..." (Nilde, casal 4); "A gente acha que é um troço incurável, que a pessoa num vai resisti por muito tempo, num vai sobrevive." (Roberto, casal 4); "Notícia do câncer é um ponto de morte." (Marta, casal 5); "Eu vô morre, a sensação era essa." (Rute, casal 6); "Eu sentia meio abatido também porque eu tinha muito medo de perdê ela." (Pedro, casal 7).

A presença do câncer de mama provocou um grande susto nos casais entrevistados, em função deles não esperarem sua chegada, gerando sentimentos de revolta e ansiedade: "Olha eu, como fui eu que achei, eu já queria resolvê logo mais como eu fui pelo hospital $x$, a gente sabe que lá tem muita gente, então eu fiquei assim ansiosa, e com pressa, preocupada!" (Lúcia, casal 2); "Foi um choque pra mim, fiquei totalmente revoltado." (Mauro, casal 3); "A gente ficô meio apavorado." (Lourdes, casal 3); "Levei um grande susto porque você imagina, aposentei-me [...] e mais me assustô porque eu não tive tempo entre a descoberta e a cirurgia." (Nilde, casal 4); "Foi um golpe muito assim, a hora que o médico falô tal o tamanho da complicação que era né? Esse câncer." (Júlio, casal 6).

Os sentimentos expressados pelos participantes apresentados anteriormente condizem com os sentimentos de medo, incerteza, sintomas de ansiedade, depressão (Ryan et al., 2005), e sentimentos de horror, impacto e pânico (Cardozo, 2002) descritos na literatura, relacionados ao momento de diagnóstico por câncer. Esses sentimentos atualizam, mais uma vez, a associação do câncer a uma doença carregada de negatividade que, momentaneamente, parece afastar qualquer sentimento de esperança para a continuidade da vida.

Parece haver uma ligação muito estreita entre câncer, sofrimento e morte neste estudo, assim como nos apontam Gomes, Skaba, Vieira (2002), ao afirmarem que a cura do câncer ainda não foi incorporada ao repertório cultural dos indivíduos. Além disso, os maridos podem sentir desesperança, impotência, intranqüilidade e medo de perderem suas esposas (Gradim, 2005; Picard et al., 2005; Cerqueira, 2004).

Ao se retomar a fala de Mauro (casal 3), percebe-se sua revolta em relação ao câncer, que pode ser compreendida a partir da concepção de que ela é uma doença reservada às pessoas más, que não condiz com a forma como ele define sua esposa: "Ela nunca negô ajuda a quem necessitasse [...] eu nunca vi ela fazê uma maldade se quer, ela sempre procurô ajudá, procurô o bem, aconselhá pro bem do próximo [...] então eu me revoltava nesse sentido." (Mauro, casal 3); "Fiquei uns seis meses revoltado, xingando todo mundo, xingando inclusive Deus." (Mauro, casal 3).

A associação entre câncer e maldade pode ser compreendida pela história do câncer. Inicialmente, acreditava-se ser uma doença adquirida por pessoas sujas física e moralmente (Sant'anna, 1997), ou seja, pessoas pecadoras estavam condenadas à doença. Sendo assim, seguindo a lógica da história, pessoas bondosas não podem desenvolver câncer. A partir disso, compreende-se o sofrimento de 
Mauro (casal 3), que, mais tarde, conformou-se com a doença da esposa e pediu a Deus que o perdoasse por ter se revoltado, o que aliviou sua culpa e possibilitou que Mauro (casal 3) ajudasse a esposa: "Aí foi passando, fui me conformando fui vendo a melhora, a situação não se agravô, ao contrário, vinha melhorando dia a dia, aí fui me conformando, depois pedi perdão a Deus, procurei me dedicá mais a ela." (Mauro, casal 3 ).

A associação entre câncer e maldade também parece ter deixado Valmir (casal 5) sem compreensão sobre a doença da esposa Marta (casal 5), sendo ela uma pessoa tão religiosa:

É, foi muito dolorido, né? Ele ficô muito chateado, eu também e, eu sempre fui assim de... mais religiosa da família, eu que vô mais à missa, falo, leio né, gosto de falá e, então, ele chegô pra mim, aí, cê reza tanto aí, o que foi te acontecê isso daí, me dexô meia chocada, mais eu falei, eu vô dá a volta [...] e graças a Deus tô dano. (Marta, casal 5)

A relação entre a confirmação da doença e a morte, para os casais entrevistados, atualiza, mais uma vez, a própria história do câncer. Receber esse diagnóstico era como ser reconhecido publicamente e socialmente como alguém impuro.

O percurso percorrido pelos casais entrevistados mostrou que o câncer de mama ainda é uma doença associada, sobretudo, ao sacrifício, experimentado por meio da provação, que é um significado historicamente utilizado desde o início da descoberta da doença (Sant'anna, 1997) até os dias atuais (Aquino, Zago, 2007).

Deus foi citado como o responsável pelo envio da enfermidade e da sua cura, ocorrendo, inclusive, como no caso de Mauro (casal 3), uma barganha com o divino.

A despeito de Aquino, Zago (2007) afirmarem que a busca religiosa em pacientes com câncer não deva ser entendida como uma forma de fuga da realidade, mas como uma possibilidade de vislumbrar um futuro apesar do sofrimento causado pela doença, ou ainda uma ajuda no processo de cura e de aceitação da doença (Teixeira, Lefèvre, 2007), entende-se que, junto da religião, a disponibilidade de outras formas de construção de sentidos para a doença possibilita ao doente, e até a seus familiares, um maior empoderamento para vivenciarem essa experiência.

Os sentidos de provação e morte relatados em relação ao câncer apontam para a necessidade da assistência interdisciplinar aos casais cuja parceira recebeu esse diagnóstico. Uma assistência com o intuito de dispor a eles outras possibilidades de construção de sentidos para a enfermidade, capazes de ajudá-los a se perceberem, também, como participantes do processo de superação da doença, assim como nos aponta Cerqueira (2004). Além disso, a desconstrução da associação da imagem do câncer à dor e ao sofrimento pode proporcionar o aumento da busca das mulheres pelos serviços de saúde para a detecção precoce da doença e, conseqüentemente, seu melhor prognóstico (Gomes, Skaba, Vieira, 2002).

\section{Considerações finais}

A aproximação aos sentidos construídos por casais para o câncer de mama da parceira mostra que eles se aproximam muito dos conceitos que a história do câncer apresenta para a doença, cujos significados mobilizam, nos indivíduos, surpresa e dor psíquica, em virtude de esperarem um desfecho de morte. Isso aponta para a necessidade de uma assistência interdisciplinar a esses casais que objetive construir, com eles, outros sentidos para o câncer e, até mesmo, possibilidades para que eles se sintam participantes do processo de superação da doença.

Todos esses significados parecem ter colocado os participantes numa posição de fragilidade, o que os fez buscar em Deus, ou no mundo divino, as forças para enfrentarem esse momento.

O discurso religioso percebido nos participantes deste estudo possibilita a reflexão sobre essa realidade no cotidiano dos profissionais de saúde que assistem essa população. A relação com o mundo divino, ao se apresentar como uma possibilidade de ajuda para os doentes e seus acompanhantes, apresenta-se, assim, como uma ferramenta de diálogo entre cuidadores e cuidados, não enquanto um discurso moralizador, mas como mais uma possibilidade de auxílio na aceitação e superação da doença. 
O estudo apresentado, ao buscar a compreensão dos sentidos que casais constroem para o câncer de mama da parceira e sobre as formas de se relacionarem com o adoecimento por essa enfermidade, amplia as possibilidades de construção de práticas assistenciais para acolher esses casais, já que os estudos realizados até então privilegiavam apenas as mulheres acometidas pelo câncer de mama.

\section{Colaboradores}

Os autores Cintia Bragheto Ferreira, Ana Maria de Almeida e Emerson Fernando Rasera participaram, igualmente, de todas as etapas de elaboração do artigo.

\section{Referências}

AQUINO, V.V.; ZAGO, M.M.F. O significado das crenças religiosas para um grupo de pacientes oncológicos em reabilitação. Rev. Latino-am. Enferm., v.15, n.1, p.42-47, 2007. Disponível em: <www.scielo.br>. Acesso em: 08 mai. 2007.

CARDOZO, M.C. Descobrindo o câncer de mama: um estudo sobre produção de sentidos. 2002. Dissertação (Mestrado) - Pontifícia Universidade Católica do Rio Grande do Sul, Faculdade Frassinetti do Recife, Recife. 2002.

CERQUEIRA, A. A dinâmica conjugal em situação de câncer de mama. 2004. Dissertação (Mestrado) - Universidade Católica de Brasília, Brasília. 2004.

EPPING-JORDAN, J.E. et al. Psychological adjustment in breast cancer: processes of emotional distress. Health Psychol., v.18, n.18, p.315-26, 1999.

FERREIRA, C.B. Representações sociais de mulheres frente à admissão hospitalar para a realização da cirurgia por câncer de mama. 2003. Dissertação (Mestrado) - Escola de Enfermagem de Ribeirão Preto, Universidade de São Paulo, Ribeirão Preto. 2003.

GERGEN, K.J. The place of the psyche in a constructed world. Theory Psychol., v.7, n.6, p.723-46, 1997. Disponível em: <www.swarthmore.edu>. Acesso em: 6 ago. 2005.

GOMES, R.; SKABA, M.M.V.F.; VIEIRA, R.J.S. Reinventando a vida: proposta para uma abordagem sócio-antropológica do câncer de mama feminina. Cad. Saúde Pública, v.18, n.1, p.197-204, 2002.

GRADIM, C.V.C. Sexualidade de casais que vivenciaram o câncer de mama. 2005. Tese (Doutorado) - Escola de Enfermagem de Ribeirão Preto, Universidade de São Paulo, Ribeirão Preto. 2005.

INSTITUTO NACIONAL DO CÂNCER. Estimativa da incidência e mortalidade por câncer no Brasil. Rio de Janeiro, 2005. Disponível em: <http://www.inca.org.br>. Acessado em: 3 jan. 2008.

Pesquisa de opinião pública dos brasileiros sobre o câncer. Rio de Janeiro, 2005. Disponível em: <http://www.inca.org.br>. Acessado em: 26 mai. 2007.

MAYAN, M.J. Una Introducción a los métodos qualitativos: módulo de entrenamento para estudiantes y profesionales. p.1-53. Disponível em: <www.ualberta.ca/ iiqm// pdfs/introduccion.pdf.2001>. Acesso em: 4 jan. 2008. 
NOGUEIRA, V.L.S.C. O diagnóstico de câncer de mama e a interação social da mulher. 2004. Dissertação (Mestrado) - Faculdade de Enfermagem, Universidade do Estado do Rio de Janeiro, Rio de Janeiro. 2004.

PICARD, L. et al. Coping strategies among couples adjusting to primary breast cancer. J. Psychosoc. Oncol., v.23, n.2-3, p.115-35, 2005.

REY, F.L.G. Pesquisa qualitativa em psicologia: caminhos e desafios. São Paulo: Pioneira. 2002.

ROSSI, L.; SANTOS, M.A. Repercussões psicológicas do adoecimento e tratamento em mulheres acometidas pelo câncer de mama. Psicol. Ciênc. Prof., v.23, n.4, p.32-41, 2003. Disponível em: <www.pol.org.br>. Acesso em: 26 abr. 2005.

RYAN, H. et al. How to recognize and manage psychological distress in cancer patients. Eur. J. Cancer Care, v.14, n.1, p.7-15, 2005. Disponível em: <www.periódicos.capes.br>. Acesso em: 17 jun. 2005.

SAEGROV, S.; HALDING, A.G. What is it like living with the diagnosis of cancer? Eur. J. Cancer Care, v.13, n.2, p.145-53, 2004. Disponível em: <www.periódicos.capes.br>. Acesso em: 24 jun. 2005.

SANT'ANNA, B.D. A mulher e o câncer na história. In: GIMENEZ, M.G.G. (Org.). A mulher e o câncer. Campinas: Psy, 1997. p.43-70.

SCHIFFRIN, D. Approaches to discourse. Massachusetts: Blackwell, 1994.

SONTAG, S. Doença como metáfora, aids e suas metáforas. São Paulo: Companhia das Letras, 2007.

SPINK, M.J. Práticas discursivas e produção de sentidos no cotidiano: aproximações teóricas e metodológicas. São Paulo: Cortez, 2000.

SPINK, M.J.; LIMA, H. Práticas discursivas e produção de sentidos: a perspectiva da psicologia social. In: SPINK, M.J. (Org.). Práticas discursivas e produção de sentidos no cotidiano: aproximações teóricas e metodológicas. São Paulo: Cortez, 2000. p.93122.

SPINK, M.J.; MEDRADO, B. Produção de sentidos no cotidiano: uma abordagem teórico-metodológica para análise das práticas discursivas. In: SPINK, M.J. (Org.). Práticas discursivas e produção de sentidos no cotidiano: aproximações teóricas e metodológicas. São Paulo: Cortez, 2000. p.41-61.

TEIXEIRA, J.J.V.; LEFÈVRE, F. Religiosidade no trabalho das enfermeiras da área oncológica: significado na ótica do discurso do sujeito coletivo. Rev. Bras. Cancerol., v.53, n.2, p.159-66, 2007.

VIEIRA, C.P.; QUEIROZ, M.S. Representações sociais sobre o câncer feminino: vivência e atuação profissional. Psicol. Soc., v.18, n.1, p.63-70, 2006. 
A lacuna de compreensão dos sentidos construídos por casais que vivenciaram o câncer de mama da parceira motivou a realização deste estudo, que objetivou descrever e analisar os sentidos que casais constroem sobre o câncer de mama da parceira e sobre as formas de se relacionar com esse adoecimento. Sete casais foram entrevistados e os dados coletados foram analisados à luz do referencial teórico do construcionismo social. Os resultados mostraram que os sentidos de provação e morte construídos para o câncer da parceira, despertaram nos participantes sentimentos de revolta e ansiedade e a relação com Deus. A partir disso, propõe-se a relevância da assistência interdisciplinar para esses casais, bem como a integração do discurso religioso como ferramenta do cuidado assistencial a essa população.

Palavras-chave: Neoplasias da mama. Significados. Diagnóstico.

\section{Meanings of the diagnosis of female breast cancer for couples who have experienced it}

The comprehension gap regarding the meanings constructed by couples who have experienced breast cancer in the female partner motivated this study. Its aim was to describe and analyze the meanings that couples construct about the female partner's breast cancer and the ways in which they relate to this illness. Seven couples were interviewed and the data gathered was analyzed in the light of the theoretical reference of social constructionism. The results showed that the meanings of probation and death constructed for the partner's cancer aroused feelings of revolt and anxiety and a relationship with God among the participants. From this, it is proposed that interdisciplinary care is important for these couples, and that religious discourse should be integrated as a tool for caring for this population.

Key words: Breast neoplasm. Meanings. Diagnosis.

\section{Sentidos del diagnóstico por cáncer de mama femenino para parejas que lo vivieron}

El vacío de comprensión de los sentidos construidos por parejas que vivieron el cancer de mama motivó la realización de este estudio que describe y analiza tales sentidos así como las formas de relacionamiento ante esta situación. Se han entrevistado siete parejas y se han analizado los datos obtenidos a la luz del referencial teórico del construccionismo social. Los resultados muestran que los sentidos de provación y muerte construidos para el cáncer de la mujer despertaron sentimientos de revuelta en los participantes así como la relación con Dios. A partir de ello se propone la relevancia de la asistencia interdisciplinaria par estas parejas y también la integración del discurso religioso como recurso del cuidado asistencial a esta población.

Palabras clave: Neoplasia mamaria. Significados. Diagnóstico. 